Bond University

Research Repository

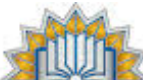 \\ *** BOND \\ UNIVERSITY
}

\section{Piloting Multimodal Learning Analytics using Mobile Mixed Reality in Health Education}

\author{
Birt, James R.; Clare, Darryl; Cowling, Michael A.
}

Published in:

2019 IEEE 7th International Conference on Serious Games and Applications for Health (SeGAH)

DOI:

10.1109/SeGAH.2019.8882435

Licence:

Other

Link to output in Bond University research repository.

Recommended citation(APA):

Birt, J. R., Clare, D., \& Cowling, M. A. (2019). Piloting Multimodal Learning Analytics using Mobile Mixed Reality in Health Education. In D. Duque, J. White, N. Rodrigues, J. L. Vilaca, \& N. Dias (Eds.), 2019 IEEE 7th International Conference on Serious Games and Applications for Health (SeGAH) (pp. 1-6). [8882435] (2019 IEEE 7th International Conference on Serious Games and Applications for Health, SeGAH 2019). https://doi.org/10.1109/SeGAH.2019.8882435

\footnotetext{
General rights

Copyright and moral rights for the publications made accessible in the public portal are retained by the authors and/or other copyright owners and it is a condition of accessing publications that users recognise and abide by the legal requirements associated with these rights.

For more information, or if you believe that this document breaches copyright, please contact the Bond University research repository coordinator.
} 


\section{Piloting Multimodal Learning Analytics using Mobile Mixed Reality in Health Education}

\author{
James Birt \\ Faculty of Society and Design \\ Bond University \\ Gold Coast, Australia \\ jbirt@bond.edu.au
}

\author{
Darryl Clare \\ School of Health, Medical and Applied \\ Sciences \\ CQUniversity \\ Brisbane, Australia \\ d.clare@cqu.edu.au
}

\author{
Michael Cowling \\ School of Engineering and Technology \\ CQUniversity \\ Brisbane, Australia \\ m.cowling@cqu.edu.au
}

\begin{abstract}
Mobile mixed reality has been shown to increase higher achievement and lower cognitive load within spatial disciplines. However, traditional methods of assessment restrict examiners ability to holistically assess spatial understanding. Multimodal learning analytics seeks to investigate how combinations of data types such as spatial data and traditional assessment can be combined to better understand both the learner and learning environment. This paper explores the pedagogical possibilities of a smartphone enabled mixed reality multimodal learning analytics case study for health education, focused on learning the anatomy of the heart. The context for this study is the first loop of a design based research study exploring the acquisition and retention of knowledge by piloting the proposed system with practicing health experts. Outcomes from the pilot study showed engagement and enthusiasm of the method among the experts, but also demonstrated problems to overcome in the pedagogical method before deployment with learners.
\end{abstract}

Keywords—mixed reality; mobile learning; technology enhanced learning; learning analytics; multimodal data; anatomy education;

\section{INTRODUCTION}

Educating using mobile mixed reality (MR) technologies comprising smartphones, augmented reality (AR), virtual reality (VR) and $3 \mathrm{~d}$ printing has emerged recently within the health sciences and medicine disciplines [1]. Specifically, mobile MR technologies have been shown to be successful for educational knowledge transfer [2,3] and familiarisation of spatial skill assessment [4]. However, while the latest mobile MR technologies have been deployed for learning with respect to spatial capabilities, these technologies require more study in the emerging field of multimodal learning analytics and summative electronic exams (eExams) using learners own smartphone devices [5].

Multimodal learning analytics seeks to investigate how combinations of various data types such as text, audio, camera, physiological and gestural spatial manipulation data sourced through traditional and new emerging technology methods can be combined to more holistically understand both the learner and learning environment [6]. In many higher education institutions paper-based exams still dominate higher stakes supervised assessment. However, there is an increasing need to bring these out-dated means of assessment into line with the digital assessment and analytic practices of today [7].

In disciplines that require the examination of spatial skills such as those in health sciences and medicine, paper based higher stakes assessment restricts examiners ability to assess spatial understanding of students [8]. This is concerning because research suggests that MR learning environments [9] and direct manipulation within MR learning environments [10] adds great value by creating a feedback loop for learning, especially in spatial disciplines such as learning anatomy.
Although the uptake of MR in education has previously been hindered by cost, expertise and capability [1], this is changing with the recent wave of low-cost immersive mobile MR hardware approaches and powerful interactive $3 \mathrm{~d}$ visualisation software platforms such as Unity3d (www.unity3d.com) [2]. Mobile MR has also been shown to increase higher achievement and lower cognitive load [11]. This combined with the capabilities of emerging smartphone devices and integrated sensors [12] creates a promising outlook for the study of multimodal learning analytics using mobile MR devices in higher education.

The objective of this pilot usability study is to explore the pedagogical possibilities of a smartphone enabled multimodal learning analytic case study for health education, specifically focused on learning the anatomy of the heart. The context for this study is the first loop of a design based research (DBR) study exploring the acquisition and retention of knowledge in using a system designed to teach anatomy by direct manipulation of a virtual heart augmented into the learners view through a combination of a physically visible $3 \mathrm{~d}$ printed cube and a smartphone mixed reality application to digitally augment the cube into a virtual heart. The specific learning is then tested by correlating the observed spatial data with specific anatomy questions, timestamping and screen recording of the spatial manipulation. This multimodal learning analytics data is then saved on a web server and observable via a digital analytics dashboard to assist with assessed observation and participant feedback.

For this first loop $(n=6)$, practising experts were recruited across the health sciences and medicine disciplines through existing networks of the authors. The experts completed a usability assessment of the developed multimodal mobile MR simulation addressing the following research question:

"What aspects of usability are most important in collecting mixed reality spatial learning analytics for providing assessment feedback?"

Outcomes from the pilot study showed engagement and enthusiasm of the method among the experts, but also demonstrated problems to overcome in the pedagogical method before deployment with learners. In particular, (i) adopting a stereoscopic view of the simulation rather than a single screen mixed reality view; (ii) increasing the fidelity of the $3 \mathrm{~d}$ model to include internal structures; (iii) representing the physical model as a heart rather than cube, and (iv) general interface improvements.

\section{BACKGROUND PROBLEM}

As educators, we are increasingly surrounded by a new breed of learner who tackles problems in new and different ways through technology [13]. This includes the learner's choices and uses of technology across their academic study and integrated context in their everyday life. These learners 
expect to be engaged by their learning environment through simulation, with participatory, interactive, sensory-rich, experimental activities (either physical or virtual), and opportunities for input [14]. This has resulted in a shift away from traditional education practice of face to face didactic lectures and tutorials in health science and medicine education to self-directed [15], electronic [16] and experiential simulation based education [17].

With growing evidence of simulation and MR visualisation improving learner outcomes [9], and mobile device ownership becoming ubiquitous [12], the implementation of mobile MR tools in health sciences and medicine education has evolved. In the health space, MR systems have been explored in the past as a way to teach disciplines such as anatomy.

Jang et al. [10] explored the value of direct manipulation of anatomical structures in a stereoscopic, $3 \mathrm{~d}$ environment using a joystick controller to manipulate and rotate the digital object. The result of their study found that there was value in this type of direct manipulation over passive viewing of the intervention, and that the spatial nature of the manipulation countered a lower spatial ability for participants. They did however note challenges with embodiment in using the joystick controller, as well as noting that results were affected very much by the need for an optimal view. Finally, they noted that the video analysis whilst useful, could have been usefully supplemented with further analytical data on manipulation.

Kucuk, Kapakin \& Goktas [11] built on this usability data by considering the effect of an AR intervention for anatomy on student achievement and cognitive load. Using a simple AR system based on the commercial product Aurasma (www.aurasma.com) now known as HP Reveal, the authors presented students with 3D models connected to markers in a 'magic book', allowing them to rotate and view the models using a mobile device. The resultant data suggested that students had reduced cognitive load from the system, and felt that the system improve their learning. However, again, a limitation was noted in making sure students got an optimal view of the objects, and felt connected to the objects which in the Kucuk et al. study were solely digital.

Through these two case studies, it can be seen that even with the successful implementations of emerging technology including mobile MR, it is often a complex picture especially related to the use of new technology [14]. Indeed, in relation to MR and AR specifically, Akcayir \& Akcayir [12] noted that there are some specific problems related to student usability of the technology. Specifically, they note that the literature identifies a need for well-designed user interfaces, with hints and learning guidance important to prevent wasted student time. They also call out technical problems with the system as still being an issue.

Further, the issue remains on how we can effectively evaluate learning and education and use of technology in education [18]. Not to mention the considerations for multimodal data gathering methods including how multimodal data sets can better inform learning and assessment methods [6] and the assessment of exams [7], which have been noted but not explored in previous studies.

Di Mitri et al. [6] contributes to this space by providing a framework for considering multimodal learning analytics. After highlighting that even the best learning analytics can only identify a subset of characteristics of learning (with the rest being surmised based on an analysis of the data), they go on to propose a model where sensor capture can be used along with machine learning to allow for the interpretation of feedback that is fed back to the learner to allow for behavioural change. Finally, they note that to complete this exercise, an important first step is to design a sensor infrastructure to allow for the collection of data that provides a set of useful 'digital snapshots' of the learner in the learner context at specific points in time.

Fluck [7] also provides some insight into the position that eExams can take in informing this space. Through a detailed review of existing eExams technology, he identifies enablers and hurdles for the implementation of eExams. Whilst acknowledging the pedagogical aspects of eExams are often idealistically noted, he noted that at this stage, workload and pragmatic concerns are more often a driver for adoption of an electronic exam framework, with curriculum transformation often poorly articulated. With this in mind, it was decided in the first round DBR loop of this study to explore the value of spatial learning analytics outside of the eExams context, with a view to reintegrating it as the eExams space matures.

Finally, in relation to the methods used for evaluation of learning technologies, Lai and Bower [18] recently published a systematic review analysing 365 papers. The authors specifically asked questions about technology evaluation constructs, research methods, evaluation instruments and technology and discipline aspects in the use of technology within education. Specifically, eight core constructs (themes) emerged including learning focus, affective elements, behaviours, design, technology, pedagogy, presence and institutional environment. The majority of education technology studies adopted mixed methods and quasiexperimental methodologies to evaluate different aspects of learning during the use.

In relation to the specifics of our study (that being experiential mobile MR and multimodal analytics), several major trends emerged from the Lai and Bower [18] paper. It was identified that mobile game based learning studies tended to more often evaluate learning and less frequently the technology aspects with mobile learning tending to evaluate teaching and pedagogy. In the science disciplines most studies evaluated learning outcomes (objectives) but less on the affective (emotional) aspects of learning. These shortcomings have also been addressed in this study and are outlined in the Research Methodology and Experimental Design section(s).

\section{RESEARCH METHODOLOGY}

Informed by the work of Bannan, Cook and Pachler [19], who suggested that design research can help to inform the development of mobile learning pedagogy, a design based research (DBR) methodology [20] was selected for the project see Fig. 1.

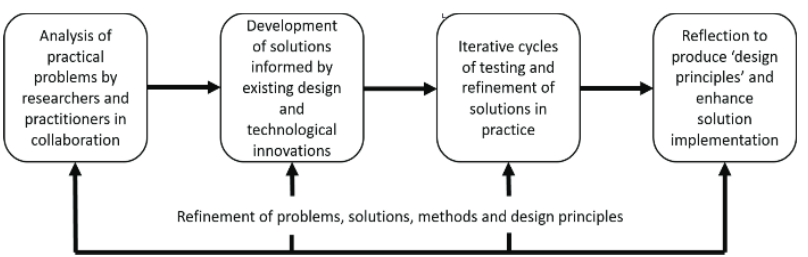

Fig. 1. Four phase design based research model adapted from Reeves. 
Specifically, the four phase DBR approach of Reeves [21] was followed through the analysis of the problem and design of the simulation solution outlined in the Experimental Design section.

Participants in the study are considered health science and medicine experts and were recruited through established networks of the author(s). These participants represent disciplines from nursing, paramedic science, first aid and ambulance medics.

The expert participants $(n=6)$ were surveyed using a usability assessment survey derived from [22] and in line with MR usability assessment outlined by Dey et al. [23] and general usability heuristics by the Nelson Norman group (www.nngroup.com/articles/usability-101-introduction-tousability). This survey has been tested in [22] but more work is required to determine scales and significance validation.

Participants were given a 10-minute primer by the lead author on the skills to be covered, and a demonstration of the tool before being asked to experiment with the simulation tool and provide usability assessment through the survey instrument outlined in Table 1. It should be noted that ethics clearance has been granted for this study.

TABLE I. USABILITY ASSESSMENT SURVEY

Ethics Reference Number: H14/12/264 - 3d printing and augmented reality for distance skills development in paramedic sciences

\begin{tabular}{|c|c|c|c}
\hline \multirow{2}{*}{ Demographics } & Sex: & Age (yrs): & $\begin{array}{c}\text { Experience (discipline } \\
\text { \& duration yrs): }\end{array}$ \\
& Male/Female & &
\end{tabular}

[Likert Scale 1 strongly disagree - 5 strongly agree - use 0 for N/A]

\begin{tabular}{ll|l|l|l|l|l|l|}
$\begin{array}{l}\text { How competent do you consider yourself when } \\
\text { using technology? }\end{array}$ & 0 & 1 & 2 & 3 & 4 & 5 \\
\hline
\end{tabular}

Please cross the most appropriate response and express an opinion (sentiment) on the visualization media(s) ...

\begin{tabular}{l}
$\begin{array}{l}\text { Accessibility: being accessible or available for use } \\
\text { at any time }\end{array}$ \\
\hline
\end{tabular}

\begin{tabular}{|l|l|l|l|l|l|l|l|} 
Learnability: allowing accomplishment of the & 0 & 1 & 2 & 3 & 4 & 5
\end{tabular}

learning objective

Cost: affordability in terms of monetary cost or

efficiency in terms of time

Satisfaction: providing confidence in meeting the

learning objective

Memorability: effectiveness or ease of re-

establishing proficiency of the learning objective

after a period (length) of time (past activities)

Usability: responsiveness, robustness, stability or

error freeness in use (e.g. motion sickness, frame

rates, bugs)

Manipulability: allowing interactive variable

manipulation e.g. rotation, time, scene objects, etc.

Navigability: allowing spatial translation of the

user(s) viewpoint

Visibility: providing a clear interface design to

observe (vision) and interpret the learning objective

\begin{tabular}{l|l|l|l|l|l|l|l|} 
Fidelity: providing an accurate representation of the & & & & & & \\
\hline
\end{tabular}

real world (including visual, touch and sound)

Communication: supporting discussion of learning

\begin{tabular}{|l|l|l|l|l|l|l|} 
objectives between stakeholders (instructor, learners, & 0 & 1 & 2 & 3 & 4 & 5
\end{tabular}

others)

Creativity: allowing emergent, creative, playful

discovery towards the learning objective

Engagement: novelty, aesthetics, or feedback to

focus learner attention and involvement on the

learning objective

Motivating: wanting to complete the learning

objective
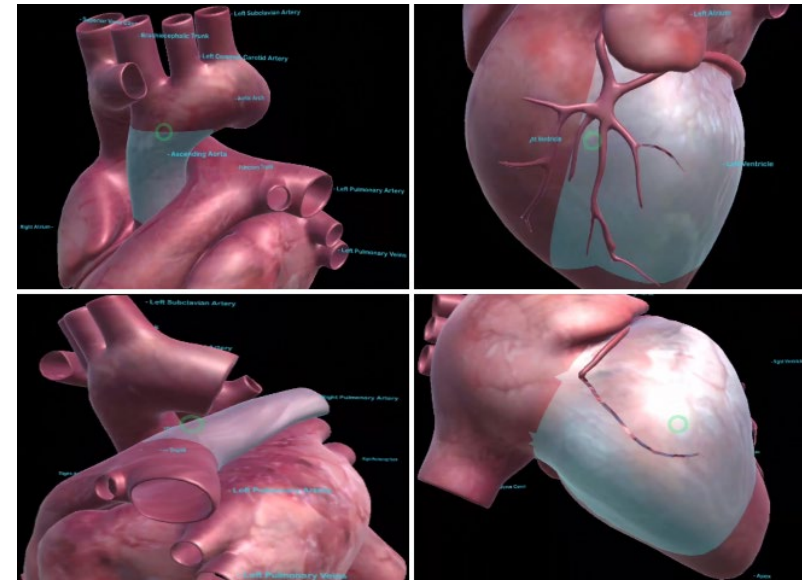

Fig. 2. Annotated heart surface anatomy modelled from McMinn et al. pg. 166-175.

\section{EXPERIMENTAL DESIGN}

The context of the experimental design was a first round DBR usability assessment test with expert health professionals to determine the feasibility of integrating what we are calling the HeartMR learning and assessment method into a health sciences and medicine classroom. The artefact of usability assessment is outlined below and represents a mobile MR spatial learning intervention focusing on the anatomical structures of the human heart represented on an android smartphone. The MR simulation visualisation was built using Autodesk Maya (autodesk.com/products/maya), Unity 3d (unity3d.com) using the MR Vuforia plugin integrated in Unity 3d 2017 and web integration tools with a web server.

The $3 \mathrm{~d}$ heart pictured in Fig. 2. was modelled using the fundamental heart anatomy from McMinn et al. [24] (pg. 166175 ) and images captured during simulation use. The model is segmented to allow for model mesh highlighting by a screen based reticle. It should be noted that for this first phase of the DBR and subsequent usability test only the surface level anatomy was modelled and annotated with considerations taken for low resolution mobile phone representation and texture draw calls. This model is represented in the Unity $3 \mathrm{~d}$ game engine as an object and is interchangeable with a more detailed model of the heart (or other organs) in future DBR loops.

The specific learning design is executed by the following steps:

a) Login identifcation and user coding - see Fig. 3. The user participant is required to first identify themselves to the system using a coded identifer for data cross referencing in the dashboard analytics system described later. The value of this identifier does not need to identify the participant, but is rather to separate analytics by participant; in a classroom context it could be a random value or could be assigned by the instructor.

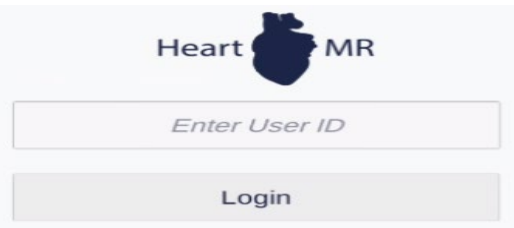

Fig. 3. HeartMR login and user coding 


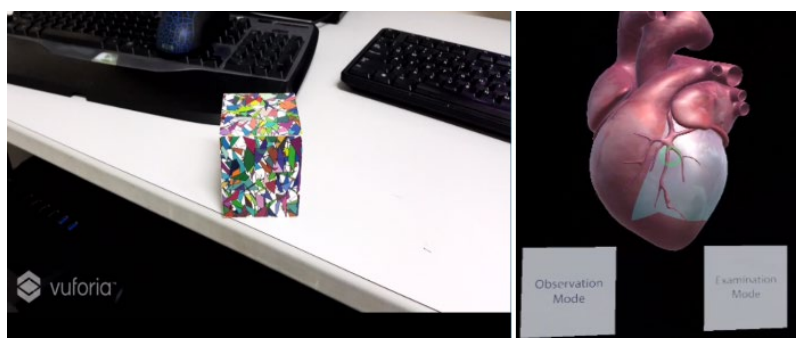

Fig. 4. Physical cube marker to mixed reality visualisation

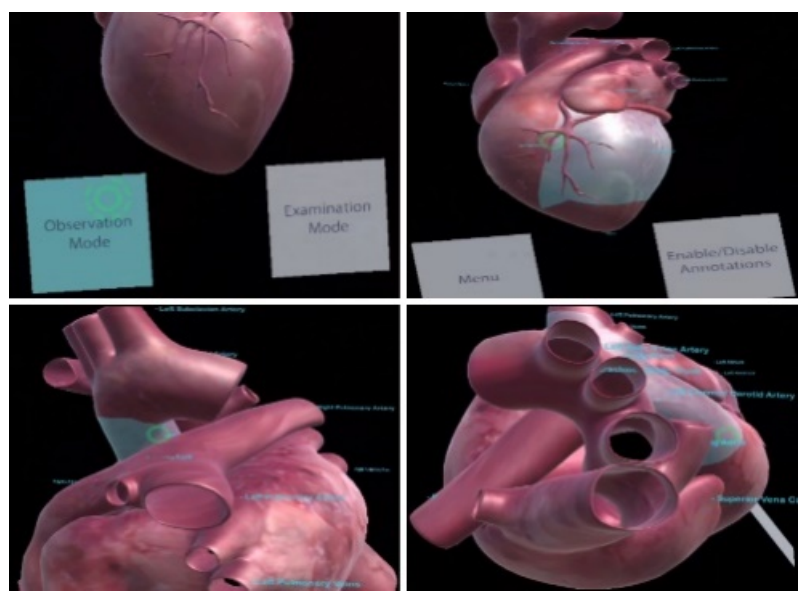

Fig. 5. Self-directed anatomical observation learning mode
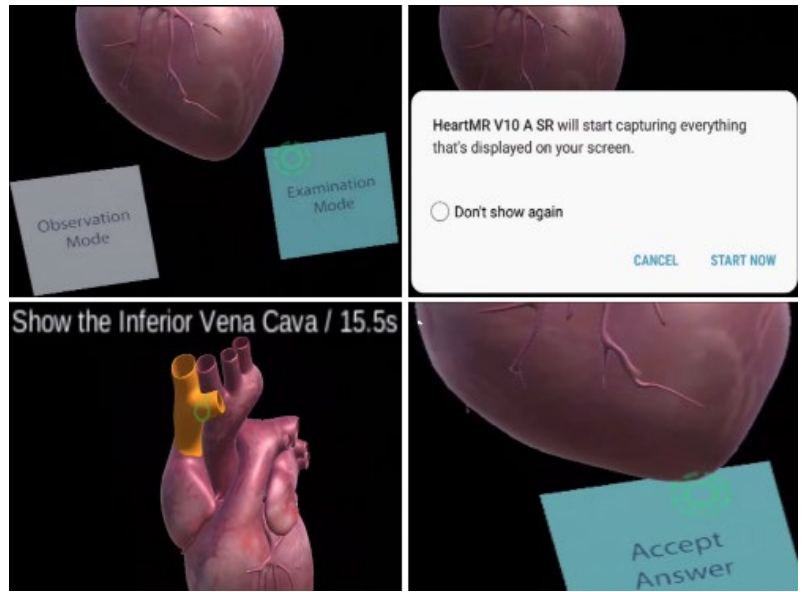

Fig. 6. Formative examination and multimodal learning analytics recording

b) Physical marker to mixed reality visualisation - see Fig. 4. The participant presents the physical $3 \mathrm{~d}$ printed cube to the smartphone camera which activates the simulation and allows both the observational learning mode or examination mode to be exectuted. The design is in line with cognitive load theory reduction as highlighted by Küçük et al. [11] and multimedia learning design [16] to reduce required learning steps and interactions.

c) Anatomical observation - see Fig. 5. The user selects the observation mode using a screen based reticle from the simulation and has the option to physically move and rotate the cube marker to explore the surface anatomy of the heart model in a self directed formative learning approach informed by Moro et al. [3], Carbonell-Carrera et al. [8] and Murad et al. [15].
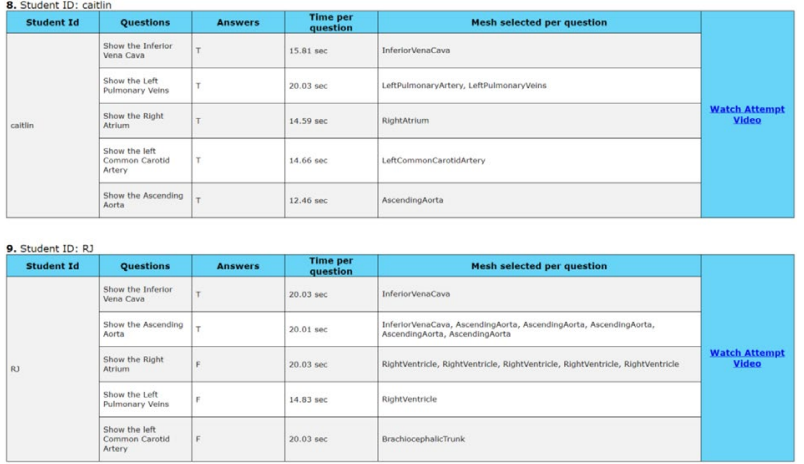

Fig. 7. Observational dashboard illustrating multimodal learning analytics

The interaction of physical directed movement to knowledge and skill aquisition is in line with previous work by Birt et al. $[4,22]$. Users can also show and hide texturual annotations to assist in the self directed learning process.

d) Anatomical examination - see Fig. 6. When the user is comfortable with the learning process they have the option to execute the examination mode. This mode informs the participant of activating the camera on the phone for the purpose of data storage (in line with recent data privacy policy rules) and opens a connection to the web server dashboard for storage of the multimodal learner analytics. The user is given 20 seconds per question to answer, gamifying the learning experience. Specifically, a JSON data structure is created and saved to the external web server which stores:

- Student id: assigned participant user code

- Questions: five randomised examination questions

- Answers: participant answers (NA, T, F) to the randomised questions

- $\quad$ Time per question: the time on task for each specific question

- Mesh selected per question: what mesh objects where highlighted during the examination process to inform observational examination

- $\quad$ Recorded screen capture video: a screen based recording capture of the participants examination

The JSON data can be visualised by the examiner in a created dashboard management system see Fig. 7. informing the examiner of the participant's summative assessment and spectate (playback) the learners mixed reality examination.

\section{RESULTS}

The first loop DBR testing of the intervention was conducted with six $(n=6)$ independent industry experts and data was collected and analyzed by the authors. The results of the administered usability survey (see Table 1) with the industry experts is presented in Table 2 (demographic results) and Table 3 (usability results), with each item ranked on a Likert Scale of 0 to 5 , where 0 is not relevant and 5 is very relevant.

During the intervention, a 360 video recording was taken of the experts including technology use, questions and answers. This was used in combination with the survey data to correlate observation of the experience to the recorded data and mapped back to the digital dashboard observation. 
TABLE II. EXPERT DEMOGRAPHIC SURVEY RESULTS

\begin{tabular}{|c|c|c|c|c|}
\hline $\boldsymbol{n}$ & Sex & Age & $\begin{array}{c}\text { Experience } \\
\text { (discipline/years) }\end{array}$ & $\begin{array}{c}\text { Technology } \\
\text { Competence }\end{array}$ \\
\hline $\boldsymbol{1}$ & F & 23 & Nursing (6y) & 3 \\
\hline $\mathbf{2}$ & F & 24 & Paramedics (6y) & 4 \\
\hline $\mathbf{3}$ & M & 54 & Ambulance Medic (30y) & 4 \\
\hline $\mathbf{4}$ & M & 33 & First Aider (6y) & 4 \\
\hline $\mathbf{5}$ & F & 45 & Ambulance Medic (6y) & 3 \\
\hline $\mathbf{6}$ & F & 56 & Nursing (13y) & 3 \\
\hline
\end{tabular}

TABLE III. EXPERT USABILITY ASSESSMENT SURVEY RESULTS

\begin{tabular}{|c|c|c|c|c|c|c|}
\hline $\begin{array}{c}\text { Assessment } \\
\text { Measure }\end{array}$ & Range & Min & Max & Mean & Median & $\begin{array}{c}\text { Std. } \\
\text { Dev }\end{array}$ \\
\hline Accessibility & 1 & 4 & 5 & 4.83 & 5.00 & 0.37 \\
\hline Learnability & 2 & 3 & 5 & 4.00 & 4.00 & 0.58 \\
\hline Cost & 2 & 3 & 5 & 4.33 & 4.50 & 0.75 \\
\hline Satisfaction & 2 & 3 & 5 & 4.00 & 4.00 & 0.58 \\
\hline Memorability & 1 & 4 & 5 & 4.50 & 4.50 & 0.50 \\
\hline Usability & 1 & 2 & 3 & 2.67 & 3.00 & 0.47 \\
\hline Manipulability & 3 & 2 & 5 & 3.67 & 4.00 & 0.94 \\
\hline Navigability & 3 & 2 & 5 & 3.50 & 3.50 & 0.96 \\
\hline Visibility & 2 & 3 & 5 & 4.00 & 4.00 & 0.58 \\
\hline Fidelity & 2 & 3 & 5 & 4.00 & 4.00 & 0.82 \\
\hline Communication & 2 & 3 & 5 & 4.00 & 4.00 & 0.82 \\
\hline Creativity & 2 & 3 & 5 & 4.33 & 4.50 & 0.75 \\
\hline Engagement & 0 & 5 & 5 & 5.00 & 5.00 & 0.00 \\
\hline Motivating & 0 & 5 & 5 & 5.00 & 5.00 & 0.00 \\
\hline
\end{tabular}

TABLE IV. EXPERT USABILITY COMMENTS

\begin{tabular}{|c|c|}
\hline$n$ & Comments \\
\hline 1 & $\begin{array}{l}\text { On the phone it was difficult to select what answer you wanted. Possibly } \\
\text { easier on VR. Please include more specific details of valves/coronary } \\
\text { arteries, etc. Inners of the heart not easily seen - a lot of black/blank } \\
\text { space. Novelty of new technology; easy to engage with app. }\end{array}$ \\
\hline 2 & $\begin{array}{l}\text { Has great potential for future learning and exciting for potential } \\
\text { applications, such as with simulation mannequins and scenario based } \\
\text { training. [usability \& manipulability] - would likely have had a better } \\
\text { experience with a VR headset rather than holding with one hand as cube } \\
\text { became occluded and difficult to regain imagery. [fidelity] - not getting a } \\
\text { great sense of touch or sound. }\end{array}$ \\
\hline 3 & $\begin{array}{l}\text { Well done - the concept is amazing as discussed to go to a VR headset } \\
\text { will definitely be the way. Expansion of usability will be to make the } \\
\text { question easier to read. And make the highlight of the object and answer } \\
\text { time longer to assist with recording. Job in progress but great first } \\
\text { attempt. }\end{array}$ \\
\hline 4 & $\begin{array}{l}\text { It's an amazing tool, very fast to learn after the first minute of getting the } \\
\text { cube into view. Perhaps a tutorial in the app to connect the user to the } \\
\text { navigation method would help. The only concern is in relation to the } \\
\text { question and answer proximity - this causes the camera to [lose] focus on } \\
\text { the cube resulting in the experience getting broken. The timer is fun I can } \\
\text { see the purpose, but the loss of tracking and timer creates problems. }\end{array}$ \\
\hline 5 & $\begin{array}{l}\text { Awesome technology. Took a few minutes to get used to how to use it, } \\
\text { but very easy to use after this. Once you knew where the cube was it was } \\
\text { easy. Perhaps this would be explicated through a VR mode and not } \\
\text { having to hold the phone. In the exam mode it was hard to see the } \\
\text { question and answer would be good to have the question floating across } \\
\text { the screen or closer to the answer. As mentioned would be good to be } \\
\text { able to use both hands on the cube - this could even be replaced with a } \\
\text { print of the heart to give touch to the user - this would illustrate structural } \\
\text { depth and projections. Job well don't to the developer the options and use } \\
\text { are limitless awesome work! }\end{array}$ \\
\hline 6 & $\begin{array}{l}\text { Could be easier to use if the phone was mounted in a VR headset and the } \\
\text { cube could be manipulated with } 2 \text { hands. Touch capability would also } \\
\text { help with this - maybe the use of a anatomical plastic model in place of } \\
\text { the cube. In the exam mode you need to place accept/question at the same } \\
\text { position - difficult to navigate up and down without losing track of the } \\
\text { cube - the reason is that you move your hand and head at the same time - } \\
\text { perhaps this would be improved with the } 2 \text { hand VR mode as mentioned. }\end{array}$ \\
\hline
\end{tabular}

In all cases, the participants responded and completed the survey with no incomplete results. Participants used the intervention for approximately 15 minutes. Results of the survey were analyzed using SPSS. Qualitative comments from the experts were also collected when reflecting on their experiences and these are presented in Table 4.

\section{DISCUSSIONS}

As noted in Table 2, participant experts came from a wide variety of different demographic areas, with both male and female participants aged from their 20's to their 50', but with a focus on paramedic science and nursing. All participants ranked their technology competence as being average or above average, echoing a desire to select practitioners that use technology in their role rather than technology enthusiasts. Experience in the discipline area was over 5 years in all cases (and sometimes up to 30), allowing testing with experts that were well versed in the discipline knowledge, allowing them to focus on the technology intervention specifically.

Table 3 presents the results of the usability measures, as outlined in detail in the methodology section. As might be expected, averages and standard deviation for the accessibility (4.83 \pm 0.37$)$, engagement $(5.00 \pm 0.00)$ and motivation (5.00 \pm 0.00 ) measures shows little variation in line with previous studies on mobile mixed reality visualization [22]. However, significant variation exists in measures related to manipulability (3.67 \pm 0.94$)$ and navigability $(3.50 \pm 0.96)$, as well as some variation in other measures and a low score in usability $(2.67 \pm 0.47)$ that is able to be teased out further in the qualitative comments outlined in Table 4.

As this proposed project is a new type of intervention, incorporating the direct manipulation of a digital visible physical object using a $3 \mathrm{~d}$ printed analogue as opposed to a remote joystick as used in [10] the low score in usability might be expected. A common comment by the participants noted the difficulty of holding both the cube and phone indicating issues with their learning affordance. An analysis of the qualitative comments suggests that this could be improved by the use of a head mount (identified by the participants as VR) for the phone to allow better correlation between field of view and user gaze, as well as the use of improved algorithms to monitor tracking. It was noted in the 360-degree observational video that through use (over a few minutes) usability improved but it was difficult to initially learn leading to fustration.

The anchoring of the buttons is also called out as a concern due to tracking loss and difficulty of selecting the buttons, relating to navigability. A suggestion that the cube be replaced by the heart model was also given, relating to manipulability.

In terms of the navigability score, the results indicate that this was also difficult, with data from the qualitative comments indicating that this was often related to the placement of the buttons in the interface and the ability to interact with static controls whilst manipulating the spatial object. Whilst attempts were made to correct this for the study, it clearly still remains an interface challenge for MR applications, in line with the findings of Akçayır and Akçayır [12] in the existent literature that interface design is primary with mixed reality applications.

On the positive side, accessibility and visibility were well regarded, consistent with [22], and engagement and motivation were also very high. Fidelity and cost scores were 
also as to be expected given previous studies, although looking at the qualitative data reveals some areas for improvement around visualisation of the inside of the heart, as well as recreating an experience that facilitates better touch and also sound (which was not considered in this study).

Finally, observation of the session itself was conducted, along with review of the 360 video, by one of the authors as a discipline expert in the area of medicine and paramedics. Notable comments from the sessions related to the discipline included,

"The ability to learn and be assessed on a complex structure such as the heart that required participants to be spatially aware added a new dimension to learning and assessment that would take place traditionally with the use of text-based resources. Participants were able to spatially perceive the location and orientation of the major structures of the heart. All participants showed high levels of engagement and motivation to learn with this novel approach. The analytics dashboard offers a promising and innovative way to assess clinical anatomy where the expert can observe what the students actually do during examination as well as receive a detailed report of the summative assessment."

This finding is consistent with current research on the use of mobile mixed reality in health education [1-4] and offers great insight into future development loops of this project and more generally mobile MR multimodal learning analytic studies.

\section{CONCLUSIONS}

Multimodal learning analytics using mobile mixed reality in health education offers promise as an innovative way to teach and assess clinical anatomy. Specifically, the study highlights the benefits of self-directed three-dimensional learning enhancing engagement and cognitive load of students with the added benefits for the examiner to observe the learner's spatial problem solving through data recording and summative analytics. As a first loop in a design based research pilot study the work shows promise but more design work is required to make the current method more user-friendly addressing issues related to usability navigation and manipulation before integration with students.

\section{REFERENCES}

[1] T. Stretton, T. Cochrane, and V. Narayan, "Exploring mobile mixed reality in healthcare higher education: A systematic review," Research in Learning Technology, vol. 26, pp. 2131-2131, 2018. doi:10.25304/rlt.v26.2131.

[2] J. Birt, Z. Stromberga, M. Cowling, and C. Moro, "Mobile mixed reality for experiential learning and simulation in medical and health sciences education," Information, vol. 9, no. 2, p. 31, 2018. doi:10.3390/info9020031.

[3] C. Moro, Z. Stromberga, and A. Stirling, "Virtualisation devices for student learning: Comparison between desktop-based (Oculus Rift) and mobile-based (Gear VR) virtual reality in medical and health science education," Australasian Journal of Educational Technology, vol. 33, no. 6, 2017. doi:10.14742/ajet.3840.

[4] J. Birt, E. Moore, and M. Cowling, "Improving paramedic distance education through mobile mixed reality simulation," Australasian Journal of Educational Technology, vol. 33, no. 6, 2017. doi:10.14742/ajet.3596.
[5] M. Cowling, M. Hillier, and J. Birt, "Integrating Mixed Reality Spatial Learning Analytics into Secure Electronic Exams," in International Conference on Innovation, Practice and Research in the Use of Educational Technologies in Tertiary Education, Geelong, 2018, pp. 330-334: ASCILITE, 2018.

[6] D. Di Mitri, J. Schneider, M. Specht, and H. Drachsler, "From signals to knowledge: A conceptual model for multimodal learning analytics," Journal of Computer Assisted Learning, vol. 34, no. 4, pp. 338-349, 2018. doi:doi:10.1111/jcal.12288.

[7] A. E. Fluck, "An international review of eExam technologies and impact," Computers \& Education, vol. 132, pp. 1-15, 2019. doi:10.1016/j.compedu.2018.12.008.

[8] C. Carbonell-Carrera and J. L. Saorin, "Virtual Learning Environments to Enhance Spatial Orientation," Eurasia Journal of Mathematics, Science \& Technology Education, journal article vol. 14, no. 3, pp. 709-719, 2018. doi:10.12973/ejmste/79171.

[9] B. Dalgarno and M. J. W. Lee, "What are the learning affordances of 3-D virtual environments?," British Journal of Educational Technology, vol. 41, no. 1, pp. 10-32, 2010. doi:doi:10.1111/j.14678535.2009.01038.x.

[10] S. Jang, J. M. Vitale, R. W. Jyung, J. B. J. C. Black, and Education, "Direct manipulation is better than passive viewing for learning anatomy in a three-dimensional virtual reality environment," Computers \& Education, vol. 106, pp. 150-165, 2017. doi:10.1016/j.compedu.2016.12.009.

[11] S. Küçük, S. Kapakin, and Y. Göktaş, "Learning anatomy via mobile augmented reality: Effects on achievement and cognitive load," Anatomical Sciences Education, vol. 9, no. 5, pp. 411-421, 2016. doi:doi:10.1002/ase.1603.

[12] M. Akçayır and G. Akçayır, "Advantages and challenges associated with augmented reality for education: A systematic review of the literature," Educational Research Review, vol. 20, pp. 1-11, 2017. doi:10.1016/j.edurev.2016.11.002.

[13] L. Corrin, S. Bennett, and L. Lockyer, "Digital natives: Exploring the diversity of young people's experience with technology," in Reshaping learning: Springer, 2013, pp. 113-138.

[14] C. Jones, R. Ramanau, S. Cross, and G. Healing, "Net generation or Digital Natives: Is there a distinct new generation entering university?," Computers \& Education, vol. 54, no. 3, pp. 722-732, 2010. doi:10.1016/j.compedu.2009.09.022.

[15] M. H. Murad, F. Coto - Yglesias, P. Varkey, L. J. Prokop, and A. L. J. M. e. Murad, "The effectiveness of self - directed learning in health professions education: a systematic review," Medical Education, vol. 44 , no. 11 , pp. $1057-1068$, 2010. doi:10.1111/j.13652923.2010.03750.x

[16] R. C. Clark and R. E. Mayer, E-learning and the science of instruction: Proven guidelines for consumers and designers of multimedia learning. New Jersey: John Wiley \& Sons, 2016.

[17] D. A. Cook et al., "Comparative effectiveness of technologyenhanced simulation versus other instructional methods: a systematic review and meta-analysis," Simulation in Healthcare, vol. 7, no. 5, pp 308-320, 2012. doi:10.1097/SIH.0b013e3182614f95.

[18] J. W. M. Lai and M. Bower, "How is the use of technology in education evaluated? A systematic review," Computers \& Education, vol. 133, pp. 27-42, 2019. doi:10.1016/j.compedu.2019.01.010.

[19] B. Bannan, J. Cook, and N. Pachler, "Reconceptualizing design research in the age of mobile learning," Interactive Learning Environments, vol. 24, no. 5, pp. 938-953, 2016. doi:10.1080/10494820.2015.1018911.

[20] T. Anderson and J. Shattuck, "Design-Based Research:A Decade of Progress in Education Research?," Educational Researcher, vol. 41, no. 1, pp. 16-25, 2012. doi:10.3102/0013189x11428813.

[21] T. Reeves, "Design research from a technology perspective," in Educational design research: Routledge, 2006, pp. 64-78.

[22] J. Birt and M. Cowling, "Assessing mobile mixed reality affordances as a comparative visualization pedagogy for design communication," Research in Learning Technology, vol. 26, 2018. doi:10.25304/rlt.v26.2128.

[23] A. Dey, M. Billinghurst, R. W. Lindeman, and J. E. Swan, "A Systematic Review of 10 Years of Augmented Reality Usability Studies: 2005 to 2014," Frontiers in Robotics and AI, Systematic Review vol. 5, no. 37, 2018. doi:10.3389/frobt.2018.00037.

[24] R. McMinn, R. Hutchings, J. Pegington, and P. Abrahams, Color atlas of human anatomy, 3rd ed. London: Wolfe, 1993. 